\title{
On the Estimation Stability of Efficiency and Economies of Scale in Microfinance Institutions
}

\section{Working Paper}

Author(s):

Bolli, Thomas (1); Vo Thi, Anh

Publication date:

2012-01

Permanent link:

https://doi.org/10.3929/ethz-a-006909474

Rights / license:

In Copyright - Non-Commercial Use Permitted

Originally published in:

KOF Working Papers 296 


\section{KOF Working Papers}

On the Estimation Stability of Efficiency and Economies of Scale in Microfinance Institutions

Thomas Bolli and Anh Vo Thi 


\section{KOF}

ETH Zurich

KOF Swiss Economic Institute WEH D 4

Weinbergstrasse 35

8092 Zurich

Switzerland

Phone +41446324239

Fax +41446321218

www.kof.ethz.ch

kof@kof.ethz.ch 


\title{
On the Estimation Stability of Efficiency and Economies of Scale in Microfinance Institutions ${ }^{1}$
}

\author{
Thomas Bolli \\ Lancaster University, Economics Department \\ LA1 4YX, Lancaster, UK \\ E-mail: bolli@alumni.ethz.ch
}

Anh Vo Thi

ETH Zurich, KOF Swiss Economic Institute

8092 Zurich, Switzerland

E-mail: nanh.vothi@gmail.com

\begin{abstract}
This paper uses a panel data set of microfinance institutions (MFI) across the world to compare several identification strategies of cost efficiency and economies of scale. Concretely, we contrast the non-parametric Data Envelopment Analysis (DEA) with the Stochastic Frontier Analysis (SFA) and a distribution-free identification based on timeinvariant heterogeneity estimates. Furthermore, we analyze differences of production functions across regions and investigate the relevance of accounting for unobserved heterogeneity across countries. The results suggest that efficiency rankings of MFIs are robust across identification strategies, but highlight the relevance of accounting for unobserved heterogeneity. We further find substantial economies of scale for a pure financial production process. However, accounting for the multi-dimensional production process of MFIs by including a measure of outreach lowers the estimated extent of economies of scale for the parametric estimations, suggesting that producing outreach creates high transaction costs and requires exploitation of local knowledge.
\end{abstract}

JEL: D24,G21

Key Words: Microfinance, Cost Efficiency, Economies of Scale, SFA, DEA, DFA, Unobserved Heterogeneity, Outreach

\footnotetext{
${ }^{1}$ Thomas Bolli and Anh Vo Thi would like to thank the Swiss National Science Foundation for financial support.
} 


\section{Introduction}

In 1976, Muhammad Yunus initiated a project that would become the Grameen Bank in 1983. The concept of microfinance was born and received increasing attention over time, culminating in a Nobel Price for Peace Yunus received in 2006. The concept had huge success. With average annual asset growth of 39\% between 2004 and 2008, the microfinance sector accumulated total assets of over US $\$ 60$ billion by 2008 (Chen et al, 2010). As a result, microfinance increasingly caught the interest of both political and financial actors, thereby sparking demand for evaluations of microfinance institutions (MFI).

Practitioners often employ an accounting-based ratio analysis. In order to develop standard definitions of financial terms and ratios donor agencies, rating firms and other organizations working in microfinance proposed a set of 20 indicators related to productivity and efficiency, such as loan officer productivity, operating expense ratio and cost per client (CGAP, 2003). In an attempt to reduce the dimensionality of the evaluation, operating expense ratio and cost per client were suggested as main criteria (CGAP, 2006; Rosenberg, 2009).

However, evaluating MFIs using accounting-based ratios faces several severe disadvantages. First, ratios provide information about efficiency in a single dimension only, hence fail to capture the multi-dimensional nature of the production process of MFIs. As a result, they provide no suitable framework or definition of efficiency (see, e.g., Brand, 2000; CGAP, 2003; Rosenberg, 2009). This disadvantage becomes particularly crucial if multiple donors with varying interests finance an MFI (Balkenhol, 2007). Secondly, the employed ratios fail to account for economies of scale and while comparing ratios within categories of size mitigates this problem to some extent, this approach assumes linearity of economies of scale (Worthington, 1998). Furthermore, such an approach does not allow to pinpoint the optimal scale of an MFI. Thirdly, ratio analysis does not identify a best practice and hence provides no benchmark to compare MFIs (Athanassopoulos and Ballantine, 1995, Flückiger \& Vassiliev, 2007). It also uses a single input only, hence does not inform about the trade-offs between inputs and the optimal input mix. Fourthly, a comparison of ratios does not account for unobserved heterogeneity due to e.g. differences in regulation, geography or demography (Balkenhol, 2007).

Literally hundreds of papers study efficiency of commercial banking in the context of frontier analysis (see, e.g., Berger \& Humphrey, 1997) for a comprehensive review of this literature). However, only relatively few studies apply frontier measures to MFIs. Using Data Envelopment Analysis (DEA), Nghiem et al. (2006) and Flückiger and Vassiliev (2007) analyze MFIs in Vietnam and Peru, respectively. Qayyum and Ahmad (2006), GutiérrezNieto et al. (2007) and Bassem (2008) analyze MFI efficiency in the regions South Asia,

Latin America and the Mediterranean zone, respectively. Furthermore, Haq et al. (2009) and Nawaz (2010) use DEA to compare MFI performance across regions. Employing the Stochastic Frontier Analysis, Hassan and Tufte (2001) study branch data of the Grameen bank 
and Masood and Ahmad (2010) analyze Indian MFIs. Hartarska and Mersland (2009) and Hartarska et al. (2009) analyze a sample of MFIs across the world using SFA and a semiparametric smooth coefficient cost function, respectively. Caudill et al. (2009) estimate a parametric cost function of MFIs in Eastern Europe and Central Asia and account for unobserved heterogeneity using a mixture model.

While most studies treat MFIs as banks, i.e. assume a purely financial production process, a few recent papers further account for outreach as the second output dimension in their analysis of efficiency. Bassem (2008) include the number of female borrowers as an indicator of outreach, while Hartarska and Mersland (2009) use the number of active borrowers. Gutiérrez-Nieto et al. (2009) calculate DEA efficiency scores including and excluding outreach, measured by the number of female borrowers and the inverse of the average loan size per GNI. They find that financial and social efficiencies display a significant, though small correlation. The SFA employed by Hermes et al. (2009) reveals a trade-off between financial and social outputs, which are measured as number of active borrowers.

This paper extends the existing literature on MFI efficiency using an unbalanced panel data set of MFIs across the world in a number of ways. First, we contrast three empirical identification strategies of MFI efficiency, namely Stochastic Frontier Analysis (SFA), a distribution-free approach (DFA) proposed by Schmidt and Sickles (1984) and Data Envelopment Analysis (DEA). Contrasting these methodologies further allows us to extend the analysis of the appropriate production process specification of Gutiérrez-Nieto et al. (2009) by comparing a pure financial and a multi-dimensional production process model across empirical identification strategies. Secondly, we exploit the global nature of our data set to analyze differences in the production process across regions. Thirdly, we address the relevance of unobserved heterogeneity. Concretely, we test the relevance of introducing country-specific intercepts in our estimation in the spirit of the true fixed effect model (Greene, 2005a,b). Fourthly, we provide evidence of the economies of scale in the production process of MFIs, allowing us to assess whether the existing MFIs have become too large or remain too small to exploit potential economies of scale.

We find that the three empirical identification strategies (SFA, DFA and DEA) yield comparatively similar results in respect to efficiency rankings, suggesting that parameterizing the production function and using a distributional assumption to identify MFI efficiency increase the efficiency of the estimation. Furthermore, we find that the production process looks surprisingly similar across regions. However, controlling for unobserved heterogeneity across countries affects efficiency rankings substantially, suggesting that comparisons of MFIs across countries need to account for these differences.

We further find that assuming a pure financial production process suggests that virtually all MFIs operate under increasing economies of scale, meaning that they should either grow or merge in order to exploit this potential source of efficiency gains. However, accounting for 
the multi-dimensional production process lowers the estimated share of MFIs operating under increasing returns to scale substantially. This might suggest that producing outreach represents a source of diseconomies of scale due to transaction costs and the relevance of local knowledge. However, the non-parametric DEA continues to indicate increasing economies of scale for all MFIs.

The second section describes the data and the employed methodologies. The results are discussed in section three and section four concludes the paper.

\section{Data and Methodology}

Based on the MixMarket database (http://www.mixmarket.org/), this paper uses an unbalanced micro-level panel data set of 796 microfinance institutions (MFI) across 88 countries in 6 regions between 2005 and 2009. After eliminating observations with only a single observation across time or missing values, 2983 observations remain in the sample. Table A1 in the appendix provides details on the distribution of observations and MFIs across countries and regions.

We present the results of two alternative output specifications. The first estimates a pure financial production process, where financial output refers to the gross loan portfolio. The second model additionally entails a measure of outreach depth, thereby capturing the social dimension of MFI output. Concretely, the multi-dimensional production process models include the inverse of the average loan size per GNI to account for outreach (Gutiérrez-Nieto et al., 2009).

Inputs contain personnel and total borrowings. The corresponding prices refer to operating expenses per personnel and financial expenses per total borrowings. Finally, following Hartarska and Mersland (2009), we include loan quality or risk in our vector of control variables, measured as the provisions for loan impairments in relation to the gross loan portfolio. We normalize all variables by the median. Table 1 provides summary statistics of the employed variables.

Table 1 about here

This paper contrasts three identification strategies of efficiency, namely Stochastic Frontier Analysis (SFA), a distribution-free approach (DFA) proposed by Schmidt and Sickles (1984) and Data Envelopment Analysis (DEA).

The SFA framework identifies efficiency via a distributional assumption (Aigner et al. 1977, Meeusen and van den Broeck 1977). Concretely, the panel data SFA proposed by Battese and Coelli (1995) assumes that inefficiency, $v_{\mathrm{i}}$, follows a half-normal distribution, i.e. $v_{\mathrm{i}}=\left|\mathrm{U}_{\mathrm{i}}\right|$, 
with $\mathrm{U}_{\mathrm{i}} \sim \mathrm{N}\left(0, \sigma_{v}\right)$. The dimensions $\mathrm{i}=\{1, \ldots, \mathrm{I}\}$ and $\mathrm{t}=\{1, \ldots, \mathrm{T}\}$ denote units of observation and time, respectively. Assuming a translog-form of the production process, the estimated cost function becomes

$$
\begin{aligned}
& C_{i t}^{*}=\alpha_{0}+\alpha_{t}+\sum_{r=1}^{R} \beta_{r} \ln y_{r i t}+\frac{1}{2} \sum_{r=1}^{R} \sum_{s=1}^{R} \beta_{r s} \ln y_{r i t} \ln y_{s i t}+\sum_{m=1}^{M-1} \gamma_{m} \ln p_{m i t}^{*} \\
& +\frac{1}{2} \sum_{m=1}^{M-1} \sum_{n=1}^{M-1} \gamma_{m n} \ln p_{m i t}^{*} \ln p_{n i t}^{*}+\frac{1}{2} \sum_{r=1}^{R} \sum_{m=1}^{M-1} \delta_{r m} \ln y_{r i t} \ln p_{m i t}^{*}+\varphi \ln r i s k_{i t}+v_{i}+v_{i t}
\end{aligned}
$$

where $C_{i t}^{*}$ and $p_{m i t}^{*}$ denote total variable costs and input prices normalized by $\mathrm{p}_{\text {Mit }}$, respectively. Concretely, $C_{i t}^{*}=C_{i t} / p_{\text {Mit }}$ and $p_{m i t}^{*}=p_{m i t} / p_{\text {Mit }}$. $\mathrm{y}_{\text {rit }}$ captures the $\mathrm{r}$ outputs, namely gross loan portfolio for the pure financial production process model and gross loan portfolio and the inverse of average loan size per GNI for the multi-dimensional production process model, respectively. Furthermore, we include the natural logarithm of risk. The error term $v_{\text {it }}$ follows a normal distribution with mean zero and standard deviation $\sigma_{v}$. Time dummies $\alpha_{t}$ capture unobserved heterogeneity across time.

The methodology developed by Jondrow et al. (1982) backs out inefficiency scores according to

$$
E\left[v_{i t} \mid \varepsilon_{i t}\right]=\frac{\sigma \lambda}{1+\lambda^{2}}\left[\frac{\phi(z)}{1-\Phi(z)}-z\right]
$$

where $z=\varepsilon_{i t} \lambda \sigma^{-1}, \lambda=\sigma_{v} \sigma_{v}^{-1}$ and $\sigma=\sqrt{\sigma_{v}^{2}+\sigma_{v}^{2}}$. Efficiency refers to the exponential of the negative inefficiency estimate, i.e. $\operatorname{eff}_{i t}=1 / \exp \left(-v_{i t}\right)$.

In order to evaluate the stability of our estimates across regions, we complement the estimates for the whole sample (SFA) with estimates for each region (SFA-R). Finally, in the spirit of Greene (2005a, 2005b) ${ }^{2}$, we account for unobserved heterogeneity in the panel data SFA by including country specific intercepts, $\alpha_{j}$, and denote the resulting estimator FE SFA for the whole sample and FE SFA-R for regional estimates, respectively.

The distribution-free approach (DFA) proposed by Schmidt and Sickles (1984) models the production process as in the SFA methodology, i.e. assumes a translog cost function. However, the methodology differs in respect to the identification of efficiency. Instead of relying on a distributional assumption, the DFA exploits the panel nature of the data to

\footnotetext{
${ }^{2}$ Unfortunately, the true fixed effect estimator that entails a dummy for each MFI does not converge.
} 
estimate individual intercepts for each MFI and interprets the deviation from the smallest intercept as inefficiency. Concretely, we estimate

$$
\begin{aligned}
& C_{i t}^{*}=\alpha_{i}+\alpha_{t}+\sum_{r=1}^{R} \beta_{r} \ln y_{r i t}+\frac{1}{2} \sum_{r=1}^{R} \sum_{s=1}^{R} \beta_{r s} \ln y_{r i t} \ln y_{s i t}+\sum_{m=1}^{M-1} \gamma_{m} \ln p_{m i t}^{*} \\
& +\frac{1}{2} \sum_{m=1}^{M-1} \sum_{n=1}^{M-1} \gamma_{m n} \ln p_{m i t}^{*} \ln p_{n i t}^{*}+\frac{1}{2} \sum_{r=1}^{R} \sum_{m=1}^{M-1} \delta_{r m} \ln y_{r i t} \ln p_{m i t}^{*}+\varphi \ln r i s k_{i t}+v_{i t}
\end{aligned}
$$

and calculate efficiency as

$$
\text { eff } f_{i}=1 / \exp \left(-v_{i}\right)=1 / \exp \left(-\left(\min \left(\alpha_{i}\right)-\alpha_{i}\right)\right)
$$

Beside of comparing efficiency estimates across methodologies and region, we also contrast estimates of economies of scale. For the SFA and the DFA, we follow Baumol et al. (1982), Kim (1986) and Iimi (2004) and calculate economies of scale as

$$
S E=\frac{1}{\sum_{r} \eta_{r}}=\frac{1}{\sum_{r}\left(\partial C / \partial Y_{r}\right) /\left(C / Y_{r}\right)}=\frac{1}{\sum_{r}\left(\partial \ln C / \partial \ln Y_{r}\right)},
$$

where $\eta_{\mathrm{r}}$ denotes the cost elasticity of output $\mathrm{r}$.

Finally, the cost-minimizing model of the nonparametric Data Envelopment Analysis (DEA) with variable returns to scale solves the minimization problem given by (see e.g. Coelli et al. 2005):

$$
\begin{gathered}
\min _{\lambda, x_{i}^{*}} p_{i}{ }^{\prime} x_{i}^{*}, \\
\text { s.t. to }-y_{i}+Y \lambda \geq 0, \\
x_{i}^{*}-X \lambda \geq 0, \\
I 1^{\prime} \lambda=1 \\
\lambda \geq 0
\end{gathered}
$$

$\mathrm{Y}$ and $\mathrm{X}$ denote matrices of outputs and inputs, respectively. Total cost efficiency is obtained by calculating 
In order to evaluate the economies of scale, we run an additional DEA that instead of assuming variable returns to scale imposes non-increasing returns to scale, i.e. changes the restriction $I I^{\prime} \lambda=1$ in formula (6) to $I I^{\prime} \lambda \leq 1$. If the two estimates turn out unequal, the firm exhibits increasing returns to scale.

Table 2 about here

A detailed discussion of the strengths and weaknesses of these three methodologies goes beyond the scope of this paper (see, e.g., Murillo, 2004 for an overview). This paragraph summarizes the main arguments. First, unlike the DEA, both the SFA and the DFA require an assumption concerning the functional form of the production process. The SFA further assumes a particular distribution of inefficiency. In short panels, the DFA suffers from the incidental parameter problem (Lancaster 2000). While the DEA alleviates these issues, the deterministic nature of its frontier ignores any measurement or specification error and makes the estimates susceptible to outliers. Furthermore, the DEA suffers from the curse of dimensionality and enriching the specification, e.g. integrating panel data, is not straightforward.

\section{Results}

Tables A3a, A3b and A3c in the appendix display the estimation results of the SFA and DFA approaches, allowing us to asses the adequacy of our econometric strategy and production process specification. Concretely, the results in Table A3a support our production process specification in the sense that the coefficients of outputs and price of borrowing have the expected positive sign. Furthermore, the coefficients of gross loan portfolio and the price of borrowing remain stable across the displayed methodologies, i.e. the panel SFA, the panel SFA including country fixed effects and DFA approach for a financial and multi-dimensional production process specification. As Bernstein (1996) and Hartarska and Mersland (2009), we find that risk increases variable costs, though the coefficient remains insignificant in the latter.

Tables A3b and A3c show the estimates of individual panel SFAs for each region assuming a financial and multi-dimensional production process, respectively. Columns 1-6 do not account for unobserved heterogeneity across countries while columns 7-12 present estimates including country fixed effects. The coefficients of gross loan portfolio remain stable across methodology and region, though they turn out somewhat higher in the regions East Asia/ Pacific, Europe/ Central Asia and Latin America. However, we find some variation in the 
coefficients of outreach depth. Concretely, the coefficient remains substantially lower in Africa and South Asia. This implies that producing outreach depth is cheaper in these regions, thereby suggesting that transaction costs are lower. In respect to risk, our results suggest that variable costs in the regions Europe/Central Asia, Latin America and Middle East/North Africa increase in risk, but not otherwise. Controlling for unobserved heterogeneity between countries doesn't affect these results. However, due to the small sample size, the share of variation in the error term explained by inefficiency (gamma) turns insignificant in South Asia after including country dummies.

Table 3 presents mean efficiency estimates across methodologies and regions. The results display substantial heterogeneity in the estimated level of efficiency across methodologies. Concretely, in accordance with Greene (2004), the SFA results including country fixed effects yields the highest estimates, as the country dummies might snatch up parts of inefficiency. Since the DFA methodology assumes that all time-invariant heterogeneity corresponds to efficiency, it results in the lowest efficiency estimates as proposed by Greene (2004). Hence, as expected, the DFA efficiency levels differ dramatically from the efficiency levels based on the SFA. The DFA results correspond closely to those of the entirely non-parametric DEA, reflecting the fact that the DEA treats all productivity differences as efficiency. This pattern of efficiencies across methodologies emerges for both a financial and multi-dimensional production process model. As expected, the estimated efficiencies are higher in the multidimensional case. This difference appears most pronounced in the case of the various SFA estimates, while the distributional-free DFA and DEA approaches suggest a similar level of efficiency for both production process specifications.

Table 3 about here

A comparison of regions based on a financial production process suggests that on average, efficiency is highest in Europe/Central Asia, followed by Latin America and South Asia. Africa and Middle East/North Africa constitute the next group of regions and East Asia/Pacific features the least efficient MFIs. Similarly, Nawaz (2010) finds that MFIs in Middle East/North Africa and South Asia are less efficient than African MFIs. While Hassan and Sanchez (2009) also find a high efficiency level of South Asian MFIs, their results suggest that those operating in Middle East/North Africa and Latin America display similar efficiency levels. Furthermore, our results are broadly consistent with those of Hassan and Sanchez (2009).

Accounting for the multi-dimensional production process of MFIs suggests three groups of efficiency levels, which is highest in Europe/Central Asia and Latin America followed by Africa and East Asia/Pacific, while the Middle East/North Africa and South Asia form the 
bottom. Hence, regional efficiency level estimates depend strongly on the choice of the production process, reflecting differences in the costs of producing outreach, e.g. due to the relevance of transaction costs and local knowledge in the production process.

Table 4 displays the spearman rank correlations between the efficiency estimates for the whole sample as well as for each region separately. In order to facilitate the comparison, we use the average efficiency values over time for DEA. Furthermore, we calculate correlations to regional SFA estimates as the average correlation within each region (see Table A4).

Table 4 about here

These results show, that the SFA for the whole sample barely differs from estimates based on regional subsamples, which doesn't surprise given that production function estimates remained stable across regions. The only exception is the multi-dimensional production process in the region Middle East/North Africa, where the correlation for SFA and FE SFA with their regional counterparts still reaches 0.89 and 0.67 , respectively.

Table 4 further allows to assess the adequacy of the distributional assumption of the SFA by comparing it to the parametric, but distribution-free DFA approach. Since the spearman correlations exceed 0.95 in every region, our findings support the use of the more efficient SFA methodology. However, the DFA merely relaxes the distributional assumption of the SFA but remains to parameterize the production technology. The DEA on the other hand provides fully non-parametric estimates of efficiency. Again, these results suggest that the econometric assumptions underlying the SFA approach appear to hold in this setup.

Concretely, we find that the average spearman correlation between DEA and SFA amount to 0.94 and 0.88 for the financial and multi-dimensional production process, respectively. Inspecting the correlations within each region reveals that the lowest correlations of 0.73 and 0.77 for the multi-dimensional production process in East Asia/ Pacific and Latin America remain very high.

Furthermore, comparing a simple panel SFA to a corresponding model that includes country dummies allows to assess the relevance of unobserved heterogeneity across countries. The overall spearman correlation amounts to 0.48 and 0.37 for the financial and multi-dimensional production process, respectively. These relatively low correlations suggest that this model feature is relevant, i.e. that differences in e.g. regulatory environment, geography and demography, affect productivity of MFIs substantially. This finding highlights the relevance of research analyzing environmental influences on MFI efficiency (see, e.g., Nghiem et al., 2009, Hermes et al., 2009, Hartarska and Mersland, 2009, Nawaz, 2010).

Differentiating between regions reveals that unobserved heterogeneity across countries matters particularly for the Middle East/North Africa region, where the spearman correlations 
drop to 0.08 and 0.29 . However, accounting for regional differences in the production process alleviates these problems to some extent as the spearman correlations between the regional SFA and FE SFA go up to 0.26 and 0.46 . However, the substitutability of regional estimates and country dummies does not apply for other regions, where the addition of country dummies results in a similar correlation independent of whether referring to a global or regional production process.

Finally, Table 4 allows us to assess the relevance of accounting for the social dimension in the production process specification. Similar to Gutiérrez-Nieto et al. (2009), we find a high correlation between efficiency estimates including and excluding outreach. Particularly the distribution-free approaches, DFA and DEA, show little variation in the estimated efficiency rankings, thereby replicating the stability of these estimators in respect to the estimated level of efficiency. This finding suggests that good management practices in an MFI improve efficiency in both the financial and social dimension.

In order to assess economies of scale for both parametric and non-parametric estimations, Table 5 displays the share of firms for which the methodology suggests increasing returns to scale. Using a financial production process model suggests that all firms exhibit increasing returns to scale across all methodologies. In other words, the analyzed MFIs are too small.

However, the results become less straightforward to interpret once we account for the multidimensional nature of the MFI production process. The non-parametric DEA remains to indicate that all MFIs operate under increasing returns to scale. This finding aligns well with the correlation of 0.97 between efficiency estimates of financial and multi-dimensional production process, i.e. indication that the DEA results depend little on the production process model. The results of the DFA indicate that $61 \%$ of MFIs operate under increasing returns to scale. While this value lies substantially below the $100 \%$ estimated for the financial production process model, it remains to be relatively high. The results based on SFA on the other hand suggest a much lower share of firms operating under increasing returns to scale. Concretely, the estimated share lies between $30 \%$ and $39 \%$ for the SFAs that do not account for unobserved heterogeneity and drops to $21 \%$ and $24 \%$ for estimates that include country dummies in the estimation. A potential explanation might be that producing small loans represents a source of diseconomies of scale due to transaction costs and the relevance of local knowledge. These results highlight the relevance of accounting for the multidimensional production process of MFIs and suggest that where MFIs attempt to take advantage of economies of scale, they need to adapt the organizational style in a way that allows them to account for the specificities of the local market.

Analyzing differences in the estimated relevance of economies of scale suggests that local knowledge is the least important in Africa and Europe/ Central Asia. The results remain unstable across methodologies for Middle East/ North Africa and South Asia, but suggest that local knowledge has very high importance for East Asia/ Pacific and Latin America. 
Table 5 about here

\section{Conclusions}

We have exploited an unbalanced panel data set of microfinance institutions across the world to assess the stability of efficiency estimates across methodologies and regions and find relatively stable results. However, our findings highlights the importance to control for unobserved heterogeneity across countries. Exploring the reasons for this unobserved heterogeneity and pinning down its determinants and potential remedies provides a promising route of continuing the analysis of MFI efficiency.

The paper also explores economies of scale in the microfinance sector. The findings based on a pure financial production process model suggest that all MFIs operate under increasing returns to scale. However, accounting for the multi-dimensional production process lowers the estimates of the parametric methodologies, suggesting that producing small loans efficiently requires access to local knowledge. The estimates of the non-parametric DEA are not affected though.

\section{References}

Aigner, D., C.K. Lovell and P. Schmidt (1977), "Formulation and estimation of stochastic Frontier production models", Journal of Econometrics, 6, 21-37.

Athanassopoulos, A. D. and J. A. Ballantine (1995), "Ratio and Frontier Analysis for Assessing Corporate Performance: Evidence from the Grocery Industry in the UK", Journal of the Operational Research Society, 46: 427-440.

Balkenhol, B. (editor) (2007), "Microfinance and Public Policy: Outreach, Performance, and Efficiency", Palgrave MacMillan and International Labor Organization.

Bassem, B.S. (2008), "Efficiency of Microfinance Institutions in the Mediterranean: An Application of DEA", Transition Study Review, 15: 343-354.

Battese, G.E. and T.J. Coelli (1995), "A Model for Technical Inefficiency Effects in a Stochastic Frontier Production Function for Panel Data”, Empirical Economics, 20, 325-332.

Bauer, P.W., A.N. Berger, G.D. Ferrier and D.B. Humphrey (1998), “Consistency Conditions for Regulatory Analysis of Financial Institutions: A Comparison of Frontier Efficiency Methods", Journal of Economics and Business, 50, 85-114.

Baumol, W., J. Panzar, and R. Willig (1982), „Contestable markets and the theory of industry structure", San Diego: Harcourt Brace and Jovanovich.

Berger, Allen N., and D. Humphrey (1997), "Efficiency of financial institutions: International Survey and Directions for Future Research", European Journal of Operational Research, 98, pp. 175-212.

Bernstein, D. (1996), “Asset Quality and Scale Economies in Banking”, Journal of Economics and Business, 48, 157-166.

Brand, M. (2000), "More Bang for the Buck: Improving Efficiency", MicroBanking Bulletin, Issue 4, February. 
Caudill, S.P., D.M. Gropper, and V. Hartarska (2009), "Which Microfinance Institutions Are Becoming More Cost Effective with Time? Evidence from a Mixture Model", Journal of Money, Credit, and Banking, 41, 651-672.

CGAP (2003), "Definitions of Selected Financial Terms, Ratios, and Adjustments for Microfinance", $3^{\text {rd }}$ edition.

CGAP (2006), "Good Practice Guidelines for Funders of Microfinance", $2^{\text {nd }}$ edition.

Chen, G., R. Stephen, and X. Reille (2010), "Growth and Vulnerabilities in Microfinance", CGAP Focus Note No. 61.

Coelli, T., D. Rao, C., O'Donnell and C. Battese (2005), “An introduction to efficiency and productivity analysis", 2ndEdition, Springer.

Flückiger, Y. and A. Vassiliev (2007), "Efficiency in Microfinance Institutions: An Application of Data Envelopment Analysis to MFIs in Peru", in "Microfinance and Public Policy: Outreach, Performance, and Efficiency", edited by Bernd Balkenhol, Palgrave MacMillan and International Labor Organization.

Greene, W. (2004), "Distinguishing between heterogeneity and inefficiency: Stochastic frontier analysis of the world health organization's panel data on national health caresystems", Health Economics, 13, 959-980.

Greene, W. (2005a), "Fixed and random effects in stochastic frontier models", Journal of Productivity Analysis, 23, 7-32.

Greene, W. (2005b), "Reconsidering heterogeneity in panel data estimators of the stochastic frontier model", Journal of Econometrics, 126, 269-303.

Gutiérrez-Nieto, B., C. S. Cinca and C. M. Molinero (2007), "Microfinance Institutions and Efficiency", Omega, 35, 131-142.

Gutiérrez-Nieto, B., C. Serrano-Cinca1, and C. Mar Molinero (2009), "Social Efficiency of Microfinance Institutions", Journal of the Operational Research Society, 60, 104-119.

Hartarska, V., and R. Mersland (2009), "Which Governance Mechanisms Promote Efficiency in Reaching Poor Clients? Evidence from Rated Microfinance Institutions", European Financial Management, forthcoming.

Hartarska, V., C.F. Parmeter and R. Mersland (2009): Scope Economies in Microfinance: Evidence from Rated MFIs, unpublished.

Hassan, M.K., and B. Sanchez (2009), "Efficiency Analysis of Microfinance Institutions in Developing Countries", Networks Financial Institute at Indiana State University Working Paper, 12.

Hassan, M. K., and D. R. Tufte (2001), "The X-efficiency of a group based lending institution: the case of Grameen Bank", World Development, 29, 1071-1082.

Hermes, N., R. Lensink and A. Meesters (2009), Financial Development and the Efficiency of Microfinance Institutions, http://ssrn.com/abstract=1396202.

Iimi, A. (2004), "Banking sector reforms in Pakistan: economies of scale and scope, and cost complementarities", Journal of Asian Economics, 15, 507-528.

Jondrow, J., C.A.K., Lovell, I.S., Materov and P. Schmidt (1982), "On the estimation of technical inefficiency in the stochastic frontier production function model", Journal of Econometrics, 19, 233-238.

Kim, H.(1986), "Economies of scale and economies of scope in multiproduct financial institutions: Further evidence from credit unions", Journal of Money, Credit and Banking, 18, 220-226.

Lancaster, T. (2000), “The incidental parameter problem since 1948”, Journal of Econometrics, 95, 391-413.

Masood, T., and M.I. Ahmad (2010), “Technical Efficiency of Microfinance Institutions in India”, MPRA Paper, 25454. 
Meeusen, W., and J. van den Broeck (1977), "Efficiency estimation from Cobb-Douglas Production functions with composed error", International Economic Review, 18, 435444.

Murillo-Zamorano, L.R. (2004), "Economic Efficiency and Frontier Techniques", Journal of Economic Surveys, 18, 33-45.

Nawaz, A. (2010), "Efficiency and Productivity of Microfinance: Incorporating the Role of Subsidies", Centre Emile Bernheim Working Paper, 9.

Nghiem, H., T. Coelli, and D. S. P. Rao (2006), "The efficiency of microfinance in Vietnam: Evidence from NGO schemes in the north and the central regions", International Journal of Environmental, Cultural, Economic and Social Sustainability, 25, 71-78.

Qayyum, A., and M. Ahmad (2006), "Efficiency and Sustainability of Micro Finance", MPRA Working Paper, 11674.

Rosenberg, R. (2009), "Measuring Results of Microfinance Institutions: Minimum Indicators that Donors and Investors Should Track", CGAP Technical Guide.

Schmidt, P. and R.C. Sickles (1984), "Production frontiers and panel data", Journal of Business \& Economic Statistics, 2, 367-374.

Worthington, A. C. (1998), "The Application of Mathematical Programming Techniques to Financial Statement Analysis: Australian Gold Production and Exploration", Australian Journal of Management, 23, 97-113. 


\section{Tables}

Table 1: Summary Statistics of Outputs, Inputs, Prices and Costs

\begin{tabular}{|c|c|c|c|c|c|c|}
\hline Variable & Definition & Obs & Mean & Std. Dev. & Min & Max \\
\hline $\mathrm{q} 1$ & Gross loan portfolio in million $\$$ & 2983 & 45.3 & 168 & 0.06 & 3040 \\
\hline q2 & Inverse of the average loan balance per borrower per GNI & 2983 & 0.06 & 0.09 & 0.0003 & 0.93 \\
\hline $\mathrm{p} 1$ & Operating expenses per personnel in million $\$$ & 2983 & 1.58 & 1.65 & 0.01 & 49.2 \\
\hline p2 & Financial expenses per borrowings in $\$$ & 2983 & 131.68 & 2859.09 & 0.01 & 134874 \\
\hline $\mathrm{C}$ & Total expenditures in million $\$$ & 2983 & 999 & 3420 & 1.53 & 79000 \\
\hline Risk & Provisions for loan impairments in $\%$ & 2983 & 3.26 & 4.73 & 0.01 & 91.79 \\
\hline $\mathrm{x} 1$ & Personnel in \$ & 2983 & 530.42 & 2079.66 & 2 & 38545 \\
\hline $\mathrm{x} 2$ & Totalborrowings in million $\$$ & 2983 & 19 & 69.5 & 0.00001 & 2160 \\
\hline
\end{tabular}

Table 2: Overview of Employed Estimation Techniques and Identification Strategies

\begin{tabular}{|c|cc|}
\hline & Pooled Estimates & Regional Estimates \\
\hline Stochastic Frontier Analysis & SFA & SFA-R \\
SFA with Country Dummies & FE SFA & FE SFA-R \\
Distributional Free Approach & DFA & \\
Data Envelopment Analysis & DEA & \\
\hline
\end{tabular}

Table 3: Efficiency Means

\begin{tabular}{|c|c|c|c|c|c|c|}
\hline Financial & SFA & SFA-R & DFA & DEA & FE SFA & FE SFA-R \\
\hline Africa & 0.23 & 0.42 & 0.07 & 0.11 & 0.58 & 0.59 \\
\hline East Asia/ Pacific & 0.17 & 0.44 & 0.06 & 0.08 & 0.51 & 0.49 \\
\hline Europe/ Central Asia & 0.39 & 0.34 & 0.13 & 0.22 & 0.60 & 0.67 \\
\hline Latin America & 0.37 & 0.37 & 0.12 & 0.19 & 0.54 & 0.51 \\
\hline Middle East/ North Africa & 0.21 & 0.35 & 0.07 & 0.11 & 0.62 & 0.70 \\
\hline South Asia & 0.29 & 0.63 & 0.10 & 0.12 & 0.67 & 0.83 \\
\hline Total & 0.28 & 0.39 & 0.09 & 0.14 & 0.56 & 0.57 \\
\hline \multicolumn{7}{|l|}{ Multidimensional } \\
\hline Africa & 0.22 & 0.45 & 0.08 & 0.12 & 0.65 & 0.65 \\
\hline East Asia/ Pacific & 0.22 & 0.55 & 0.08 & 0.10 & 0.65 & 0.68 \\
\hline Europe/ Central Asia & 0.39 & 0.36 & 0.15 & 0.22 & 0.65 & 0.69 \\
\hline Latin America & 0.46 & 0.45 & 0.17 & 0.21 & 0.63 & 0.62 \\
\hline Middle East/ North Africa & 0.10 & 0.45 & 0.03 & 0.04 & 0.55 & 0.57 \\
\hline South Asia & 0.14 & 0.45 & 0.05 & 0.05 & 0.62 & 0.60 \\
\hline Total & 0.33 & 0.46 & 0.12 & 0.15 & 0.64 & 0.65 \\
\hline
\end{tabular}


Table 4: Spearman Correlations of Efficiency Estimates

\begin{tabular}{|c|c|c|c|c|c|c|c|c|c|c|c|c|c|}
\hline \multirow[t]{2}{*}{$\begin{array}{l}\text { Full } \\
\text { Sample } \\
\end{array}$} & & \multicolumn{6}{|l|}{ Financial } & \multicolumn{6}{|l|}{$\begin{array}{c}\text { Multi- } \\
\text { Dimensional } \\
\end{array}$} \\
\hline & & SFA & SFA-R & DFA & DEA & FE SFA & FE SFA-R & SFA & SFA-R & DFA & DEA & FE SFA & FE SFA-R \\
\hline \multirow[t]{6}{*}{ Financial } & SFA & 1.00 & & & & & & & & & & & \\
\hline & SFA-R & 0.96 & 1.00 & & & & & & & & & & \\
\hline & DFA & 0.98 & 0.93 & 1.00 & & & & & & & & & \\
\hline & DEA & 0.94 & 0.87 & 0.90 & 1.00 & & & & & & & & \\
\hline & FE SFA & 0.48 & 0.59 & 0.48 & 0.42 & 1.00 & & & & & & & \\
\hline & FE SFA-R & 0.56 & 0.61 & 0.56 & 0.49 & 0.95 & 1.00 & & & & & & \\
\hline \multirow[t]{6}{*}{ Multi-Dim } & SFA & 0.88 & 0.83 & 0.88 & 0.83 & 0.31 & 0.44 & 1.00 & & & & & \\
\hline & SFA-R & 0.84 & 0.87 & 0.83 & 0.75 & 0.46 & 0.47 & 0.95 & 1.00 & & & & \\
\hline & DFA & 0.89 & 0.84 & 0.92 & 0.81 & 0.35 & 0.46 & 0.97 & 0.91 & 1.00 & & & \\
\hline & DEA & 0.91 & 0.83 & 0.89 & 0.97 & 0.37 & 0.46 & 0.88 & 0.79 & 0.85 & 1.00 & & \\
\hline & FE SFA & 0.41 & 0.52 & 0.43 & 0.36 & 0.86 & 0.85 & 0.37 & 0.51 & 0.41 & 0.36 & 1.00 & \\
\hline & FE SFA-R & 0.50 & 0.53 & 0.51 & 0.43 & 0.80 & 0.84 & 0.52 & 0.56 & 0.51 & 0.44 & 0.91 & 1.00 \\
\hline
\end{tabular}

Notes: Correlations with regional estimates represent the average correlation across regions (see Table A5). Correlations with DEA are calculated based on average efficiency scores of DEA across time.

Table 5: Share of firms with increasing economies of scale by methodology and region

\begin{tabular}{|c|c|c|c|c|c|c|c|c|c|c|c|c|}
\hline & \multicolumn{6}{|l|}{ Financial } & \multicolumn{6}{|l|}{$\begin{array}{c}\text { Multi- } \\
\text { Dimensional } \\
\end{array}$} \\
\hline & SFA & SFA-R & DFA & DEA & FE SFA & FE SFA-R & SFA & SFA-R & DFA & DEA & FE SFA & FE SFA-R \\
\hline Africa & 1.00 & 0.96 & 1.00 & 0.99 & 1.00 & 0.96 & 0.63 & 0.82 & 0.90 & 0.98 & 0.45 & 0.69 \\
\hline East Asia/ Pacific & 0.98 & 0.94 & 1.00 & 0.98 & 0.99 & 0.94 & 0.21 & 0.26 & 0.57 & 0.98 & 0.10 & 0.14 \\
\hline Europe/ Central Asia & 1.00 & 1.00 & 1.00 & 0.97 & 1.00 & 1.00 & 0.48 & 0.49 & 0.76 & 0.97 & 0.42 & 0.48 \\
\hline Latin America & 0.99 & 0.99 & 1.00 & 0.96 & 1.00 & 1.00 & 0.21 & 0.07 & 0.55 & 0.96 & 0.13 & 0.02 \\
\hline Middle East/ North Africa & 1.00 & 1.00 & 1.00 & 0.94 & 1.00 & 1.00 & 0.13 & 0.50 & 0.40 & 0.94 & 0.09 & 0.59 \\
\hline South Asia & 1.00 & 0.97 & 1.00 & 0.99 & 1.00 & 0.97 & 0.16 & 0.66 & 0.43 & 0.98 & 0.09 & 0.10 \\
\hline Total & 1.00 & 0.98 & 1.00 & 0.97 & 1.00 & 0.98 & 0.30 & 0.39 & 0.61 & 0.97 & 0.21 & 0.24 \\
\hline
\end{tabular}




\section{Appendix}

Table A1: Distribution of Observations across Countries and Regions

\begin{tabular}{|c|c|c|c|c|c|c|c|c|}
\hline Region/Country & \#MFI & \# Obs & Region/Country & \#MFI & \# Obs & Region/Country & \#MFI & \# Obs \\
\hline Africa & & & Europe/ Central Asia & & & Middle East/ North Africa & & \\
\hline Angola & 1 & 3 & Albania & 6 & 22 & Egypt & 9 & 35 \\
\hline Benin & 8 & 26 & Armenia & 9 & 36 & Jordan & 7 & 24 \\
\hline Burkina Faso & 2 & 5 & Azerbaijan & 15 & 53 & Lebanon & 1 & 2 \\
\hline Burundi & 1 & 2 & Bosnia & 14 & 66 & Morocco & 9 & 35 \\
\hline Cameroon & 4 & 14 & Bulgaria & 8 & 23 & Palestine & 4 & 9 \\
\hline Chad & 1 & 2 & Croatia & 1 & 2 & Sudan & 1 & 2 \\
\hline Congo, Dem. Rep. & 1 & 3 & Georgia & 8 & 33 & Syria & 1 & 2 \\
\hline Ethiopia & 14 & 48 & Kazakhstan & 5 & 18 & Tunisia & 1 & 5 \\
\hline Gambia, The & 1 & 3 & Kosovo & 6 & 16 & Yemen & 3 & 13 \\
\hline Ghana & 17 & 55 & Kyrgyzstan & 11 & 38 & Total & 36 & 127 \\
\hline Guinea & 3 & 11 & Macedonia & 4 & 19 & & & \\
\hline Kenya & 11 & 37 & Moldova & 3 & 10 & South Asia & & \\
\hline Madagascar & 6 & 15 & Mongolia & 4 & 14 & Afghanistan & 14 & 55 \\
\hline Malawi & 3 & 9 & Montenegro & 1 & 4 & Bangladesh & 24 & 94 \\
\hline Mali & 10 & 34 & Poland & 2 & 10 & India & 57 & 204 \\
\hline Mozambique & 5 & 15 & Romania & 6 & 24 & Nepal & 18 & 62 \\
\hline Namibia & 1 & 4 & Russia & 12 & 35 & Pakistan & 15 & 53 \\
\hline Niger & 2 & 5 & Serbia & 3 & 14 & Sri Lanka & 9 & 28 \\
\hline Nigeria & 4 & 16 & Tajikistan & 15 & 53 & Total & 137 & 496 \\
\hline Rwanda & 3 & 9 & Ukraine & 2 & 8 & & & \\
\hline Senegal & 7 & 24 & Uzbekistan & 1 & 2 & & & \\
\hline South Africa & 3 & 8 & Total & 138 & 515 & & & \\
\hline Swaziland & 1 & 4 & & & & & & \\
\hline Tanzania & 7 & 22 & Latin America & & & & & \\
\hline Togo & 5 & 15 & Argentina & 5 & 18 & & & \\
\hline Uganda & 9 & 35 & Bolivia & 21 & 76 & & & \\
\hline Zambia & 2 & 5 & Brazil & 17 & 48 & & & \\
\hline \multirow[t]{2}{*}{ Total } & 132 & 429 & Chile & 4 & 17 & & & \\
\hline & & & Colombia & 20 & 73 & & & \\
\hline East Asia/ Pacific & & & Costa Rica & 8 & 28 & & & \\
\hline Cambodia & 13 & 53 & Dominican Republic & 6 & 18 & & & \\
\hline China & 2 & 7 & Ecuador & 45 & 169 & & & \\
\hline East Timor & 1 & 5 & El Salvador & 13 & 47 & & & \\
\hline Indonesia & 20 & 61 & Guatemala & 11 & 46 & & & \\
\hline Philippines & 49 & 186 & Haiti & 7 & 22 & & & \\
\hline Samoa & 1 & 5 & Honduras & 14 & 57 & & & \\
\hline Vietnam & 5 & 13 & Mexico & 36 & 118 & & & \\
\hline \multirow[t]{6}{*}{ Total } & 91 & 330 & Nicaragua & 24 & 101 & & & \\
\hline & & & Panama & 3 & 10 & & & \\
\hline & & & Paraguay & 5 & 25 & & & \\
\hline & & & Peru & 58 & 223 & & & \\
\hline & & & Venezuela & 1 & 5 & & & \\
\hline & & & Total & 298 & 1101 & & & \\
\hline
\end{tabular}


Table A2: Cross-Correlations of Outputs, Inputs, Prices and Costs

\begin{tabular}{|c|c|c|c|c|c|c|c|}
\hline Variable & $\mathrm{q} 1$ & $\mathrm{q} 2$ & $\mathrm{p} 1$ & $\mathrm{p} 2$ & $\mathrm{C}$ & Risk & $\mathrm{x}$ \\
\hline q1 & 1 & & & & & & \\
\hline $\mathrm{q} 2$ & $-0.0832 *$ & 1 & & & & & \\
\hline $\mathrm{p} 1$ & $0.1584 *$ & $0.0775^{*}$ & 1 & & & & \\
\hline $\mathrm{p} 2$ & 0.0131 & -0.0087 & -0.0115 & 1 & & & \\
\hline $\mathrm{C}$ & $0.9270^{*}$ & $-0.0421^{*}$ & $0.1885^{*}$ & 0.0048 & 1 & & \\
\hline Risk & -0.0195 & $0.1433^{*}$ & $0.2390 *$ & 0.0171 & 0.0277 & 1 & \\
\hline $\mathrm{x} 1$ & $0.5808^{*}$ & -0.0055 & $-0.0599 *$ & 0.0021 & $0.6319^{*}$ & -0.0193 & 1 \\
\hline & $0.6933^{*}$ & $-0.0582^{*}$ & $0.1474 *$ & -0.0107 & $0.5680^{*}$ & -0.0059 & 0.3499* \\
\hline
\end{tabular}

Table A3a: Estimation Results of panel SFA (SFA), panel SFA with country dummies (FE SFA) and DFA for Financial and Multidimensional Output Space

\begin{tabular}{|c|c|c|c|c|c|c|}
\hline & \multicolumn{3}{|c|}{ Financial } & \multicolumn{3}{|c|}{ Multi-Dimensional } \\
\hline & SFA & FE SFA & DFA & SFA & FE SFA & DFA \\
\hline \multirow[t]{2}{*}{ lq11 } & $0.731 * * *$ & $0.741 * * *$ & $0.651 * * *$ & $0.773^{* * *}$ & $0.804 * * *$ & $0.686^{* * * *}$ \\
\hline & $(0.010)$ & $(0.009)$ & $(0.014)$ & $(0.009)$ & $(0.008)$ & $(0.014)$ \\
\hline \multirow[t]{2}{*}{ lq21 } & & & & $0.294 * * *$ & $0.323 * * *$ & $0.242 * * *$ \\
\hline & & & & $(0.013)$ & $(0.013)$ & $(0.019)$ \\
\hline \multirow[t]{2}{*}{ q11q11 } & $0.024 * * *$ & $0.022 * * *$ & $0.023 * * *$ & $0.027 * * *$ & $0.022 * * *$ & $0.030 * * *$ \\
\hline & $(0.005)$ & $(0.004)$ & $(0.005)$ & $(0.005)$ & $(0.004)$ & $(0.005)$ \\
\hline \multirow[t]{2}{*}{$\mathrm{q} 21 \mathrm{q} 21$} & & & & $0.066 * * *$ & $0.077 * * *$ & $0.053 * * *$ \\
\hline & & & & $(0.012)$ & $(0.011)$ & $(0.014)$ \\
\hline \multirow[t]{2}{*}{ q11q21 } & & & & 0.008 & 0.002 & $0.026^{* * *}$ \\
\hline & & & & $(0.005)$ & $(0.005)$ & $(0.006)$ \\
\hline \multirow[t]{2}{*}{ lp11 } & $0.819 * * *$ & $0.852 * * *$ & $0.836 * * *$ & $0.827 * * *$ & $0.857 * * *$ & $0.847 * * *$ \\
\hline & $(0.007)$ & $(0.007)$ & $(0.008)$ & $(0.007)$ & $(0.007)$ & $(0.008)$ \\
\hline \multirow[t]{2}{*}{ p11p11 } & $-0.021 * * *$ & $-0.017 * * *$ & $-0.017 * * *$ & $-0.023^{* * *}$ & $-0.022 * * *$ & $-0.017 * * *$ \\
\hline & $(0.003)$ & $(0.003)$ & $(0.003)$ & $(0.003)$ & $(0.003)$ & $(0.003)$ \\
\hline \multirow[t]{2}{*}{ p11q11 } & $-0.007 * * *$ & $-0.011 * * *$ & $-0.012 * * *$ & $-0.010 * * *$ & $-0.011 * * *$ & $-0.011 * * *$ \\
\hline & $(0.003)$ & $(0.003)$ & $(0.003)$ & $(0.003)$ & $(0.002)$ & $(0.003)$ \\
\hline \multirow[t]{2}{*}{$\mathrm{p} 11 \mathrm{q} 21$} & & & & -0.003 & $-0.010^{* *}$ & 0.001 \\
\hline & & & & $(0.005)$ & $(0.004)$ & $(0.006)$ \\
\hline \multirow[t]{2}{*}{ lrisk21 } & $0.032 * * *$ & $0.033 * * *$ & $0.022 * * *$ & $0.027 * * *$ & $0.026^{* * *}$ & $0.020 * * *$ \\
\hline & $(0.005)$ & $(0.005)$ & $(0.005)$ & $(0.005)$ & $(0.005)$ & $(0.005)$ \\
\hline \multirow[t]{2}{*}{ Constant } & $-1.384 * * *$ & $-0.472 * *$ & $0.095 * * *$ & $-1.206^{* * *}$ & 0.054 & $0.086^{* * * *}$ \\
\hline & $(0.034)$ & $(0.219)$ & $(0.015)$ & $(0.032)$ & $(0.204)$ & $(0.017)$ \\
\hline \multirow[t]{2}{*}{ lnsigma2 } & $1.064 * * *$ & $-0.378 * * *$ & & $0.816^{* * *}$ & $-0.925 * * *$ & \\
\hline & $(0.057)$ & $(0.058)$ & & $(0.057)$ & $(0.060)$ & \\
\hline \multirow[t]{2}{*}{ gamma } & $4.043 * * *$ & $2.587 * * *$ & & $3.880 * * *$ & $2.029 * * *$ & \\
\hline & $(0.070)$ & $(0.074)$ & & $(0.070)$ & $(0.082)$ & \\
\hline $\mathrm{N}$ & 2983 & 2983 & 2983 & 2983 & 2983 & 2983 \\
\hline
\end{tabular}


Table A3b: Financial Estimation Results of Regional SFA excluding and including country dummies

\begin{tabular}{|c|c|c|c|c|c|c|c|c|c|c|c|c|}
\hline Dep: C & SFA_1 & SFA _2 & SFA_3 & SFA_4 & SFA_5 & SFA_6 & FE SFA_1 & FE SFA _2 & FE SFA_3 & FE SFA $\_4$ & FE SFA 5 & FE SFA_6 \\
\hline \multirow[t]{2}{*}{ lq1 } & 0.615 *** & $0.745^{* * *}$ & $0.824 * * *$ & $0.772 * * *$ & $0.637 * * *$ & $0.697 * * *$ & $0.674 * * *$ & $0.762 * * *$ & $0.827 * * *$ & $0.734 * * *$ & $0.718 * * *$ & $0.755 * * *$ \\
\hline & $(0.025)$ & $(0.024)$ & $(0.022)$ & $(0.014)$ & $(0.052)$ & (0.029) & $(0.023)$ & $(0.026)$ & $(0.016)$ & $(0.014)$ & $(0.041)$ & $(0.026)$ \\
\hline \multirow[t]{2}{*}{ q1q1 } & $0.061 * * *$ & $0.063 * * *$ & -0.003 & $0.021 * * *$ & 0.016 & $0.036^{* * * *}$ & $0.051 * * *$ & $0.060 * * *$ & -0.010 & $0.024 * * *$ & -0.000 & $0.024 * *$ \\
\hline & (0.017) & $(0.011)$ & $(0.011)$ & (0.008) & $(0.034)$ & $(0.011)$ & $(0.015)$ & $(0.013)$ & (0.009) & $(0.007)$ & $(0.028)$ & $(0.010)$ \\
\hline \multirow[t]{2}{*}{ lp1 } & $0.772 * * *$ & $0.771 * * *$ & $0.821 * * *$ & $0.864 * * *$ & $0.754 * * *$ & $0.607 * * *$ & $0.805 * * *$ & $0.772 * * *$ & $0.865^{* * *} *$ & $0.868 * * *$ & $0.774 * * *$ & $0.549 * * *$ \\
\hline & $(0.020)$ & $(0.021)$ & $(0.017)$ & $(0.010)$ & $(0.054)$ & (0.043) & $(0.022)$ & $(0.021)$ & $(0.015)$ & $(0.010)$ & $(0.045)$ & $(0.044)$ \\
\hline \multirow[t]{2}{*}{ p1p1 } & $-0.025 * * *$ & $-0.078 * * *$ & 0.012 & $-0.027 * * *$ & $0.038^{*}$ & $-0.054 * *$ & $-0.020 * * *$ & $-0.076 * * *$ & 0.001 & $-0.026 * * *$ & $0.047 * *$ & $-0.074 * * *$ \\
\hline & $(0.006)$ & $(0.009)$ & $(0.009)$ & $(0.007)$ & $(0.020)$ & $(0.023)$ & $(0.006)$ & $(0.009)$ & (0.008) & $(0.007)$ & $(0.018)$ & $(0.023)$ \\
\hline \multirow[t]{2}{*}{ p1q1 } & $-0.038 * * *$ & $-0.021 * * *$ & $0.020 * * *$ & -0.006 & $-0.038^{*}$ & -0.011 & $-0.035 * * *$ & $-0.020 * * *$ & 0.006 & -0.005 & $-0.035^{*}$ & $-0.022 *$ \\
\hline & $(0.009)$ & $(0.005)$ & $(0.007)$ & $(0.005)$ & $(0.021)$ & $(0.014)$ & $(0.009)$ & $(0.005)$ & (0.006) & $(0.005)$ & $(0.020)$ & $(0.011)$ \\
\hline \multirow[t]{2}{*}{ lrisk } & 0.012 & 0.002 & $0.038^{* * *}$ & $0.046 * * *$ & 0.044 & $0.030 * *$ & 0.015 & 0.004 & $0.047 * * *$ & $0.037 * * *$ & $0.050^{*}$ & 0.015 \\
\hline & $(0.014)$ & $(0.014)$ & $(0.012)$ & $(0.008)$ & $(0.028)$ & $(0.012)$ & $(0.014)$ & $(0.014)$ & $(0.011)$ & $(0.008)$ & $(0.026)$ & $(0.012)$ \\
\hline \multirow[t]{2}{*}{ Constant } & $-0.922 * * *$ & $-0.343 * * *$ & $-1.506 * * *$ & $-1.359 * * *$ & $-0.953 * * *$ & $-0.212 * *$ & $-0.576^{* *}$ & -0.403 & $0.863 * * *$ & -0.474 & $0.587 * * *$ & $-0.747 * * *$ \\
\hline & $(0.079)$ & $(0.077)$ & $(0.085)$ & $(0.044)$ & $(0.172)$ & $(0.083)$ & $(0.240)$ & $(0.256)$ & (0.306) & $(0.332)$ & $(0.222)$ & (0.127) \\
\hline \multirow[t]{2}{*}{ Insigma2 } & 0.238 & 0.125 & $0.746 * * *$ & $0.496 * * *$ & $0.550 *$ & 0.086 & $-0.578 * * *$ & 0.049 & $-0.956 * * *$ & $-0.193 * *$ & $-1.320 * * *$ & $-0.467 * * *$ \\
\hline & $(0.150)$ & $(0.168)$ & $(0.147)$ & $(0.096)$ & $(0.323)$ & $(0.145)$ & $(0.148)$ & $(0.164)$ & $(0.136)$ & $(0.096)$ & $(0.299)$ & $(0.140)$ \\
\hline \multirow[t]{2}{*}{ gamma } & $2.937 * * *$ & $3.538 * * *$ & $3.836 * * *$ & $4.038 * * *$ & $3.438 * * *$ & $2.882 * * *$ & $2.047 * * *$ & $3.478 * * *$ & $2.120 * * *$ & $3.367 * * *$ & $1.425 * * *$ & $2.305 * * *$ \\
\hline & $(0.197)$ & $(0.208)$ & $(0.182)$ & $(0.117)$ & $(0.417)$ & $(0.185)$ & $(0.204)$ & $(0.199)$ & $(0.178)$ & $(0.120)$ & $(0.453)$ & $(0.184)$ \\
\hline $\mathrm{N}$ & 429 & 330 & 500 & 1101 & 127 & 496 & 429 & 330 & 500 & 1101 & 127 & 496 \\
\hline
\end{tabular}

$*, * *$ and $* * *$ denote significances of $10 \%, 5 \%$ and $1 \%$, respectively. SFA denotes panel data stochastic frontier analysis while FE SFA include country dummies. Regions refer to "Africa" (1), "East Asia/Pacific" (2), "Europe/Central Asia" (3), "Latin America" (4), "Middle East/North Africa" (5) and "South Asia" (6).

Table A3c: Multi-Dimensional Estimation Results of Regional SFA excluding and including country dummies

\begin{tabular}{|c|c|c|c|c|c|c|c|c|c|c|c|c|}
\hline Dep: C & SFA_1 & SFA _2 & SFA_3 & SFA_4 & SFA_5 & SFA_6 & FE SFA_1 & FE SFA_2 & FESFA_3 & FE SFA_4 & FE SFA 5 & FE SFA_6 \\
\hline \multirow[t]{2}{*}{ lq1 } & $0.674 * * *$ & $0.798 * * *$ & $0.822 * * *$ & $0.832 * * *$ & $0.622 * * *$ & $0.717 * * *$ & $0.751 * * *$ & $0.814 * * *$ & $0.852 * * *$ & $0.814 * * *$ & $0.662 * * *$ & $0.807 * * *$ \\
\hline & $(0.033)$ & $(0.026)$ & $(0.027)$ & $(0.014)$ & $(0.053)$ & $(0.029)$ & $(0.029)$ & $(0.021)$ & $(0.021)$ & $(0.012)$ & $(0.050)$ & $(0.028)$ \\
\hline \multirow[t]{2}{*}{ lq2 } & $0.134 * *$ & $0.369 * * *$ & $0.347 * * *$ & $0.275 * * *$ & $0.382 * * *$ & $0.127 *$ & $0.188 * * *$ & $0.464 * * *$ & $0.330 * * *$ & $0.324 * * *$ & $0.267 * * *$ & $0.259 * * *$ \\
\hline & $(0.056)$ & $(0.046)$ & $(0.043)$ & $(0.021)$ & $(0.077)$ & $(0.067)$ & $(0.053)$ & $(0.039)$ & $(0.039)$ & $(0.021)$ & (0.074) & $(0.064)$ \\
\hline \multirow[t]{2}{*}{$\mathrm{q} 1 \mathrm{q} 1$} & $0.070^{* * *}$ & $0.059^{* * *}$ & -0.003 & $0.012^{*}$ & $0.083^{* *}$ & $0.039^{* * *}$ & $0.050^{* * *}$ & $0.059^{* * *}$ & -0.007 & $0.018 * * *$ & $0.055^{* *}$ & $0.024^{* *}$ \\
\hline & (0.019) & (0.013) & $(0.010)$ & $(0.007)$ & $(0.035)$ & (0.011) & $(0.016)$ & $(0.012)$ & (0.008) & $(0.006)$ & $(0.026)$ & $(0.010)$ \\
\hline \multirow[t]{2}{*}{$\mathrm{q} 2 \mathrm{q} 2$} & -0.005 & $0.123 * *$ & $0.107 * * *$ & $0.052 * * *$ & $-0.183^{*}$ & -0.057 & -0.010 & $0.113^{* * *}$ & $0.105^{* * *}$ & $0.042^{* *}$ & $-0.240 * * *$ & -0.046 \\
\hline & (0.038) & $(0.052)$ & $(0.029)$ & $(0.019)$ & (0.108) & $(0.074)$ & $(0.038)$ & (0.044) & $(0.026)$ & $(0.018)$ & $(0.087)$ & $(0.063)$ \\
\hline \multirow[t]{2}{*}{$\mathrm{q} 1 \mathrm{q} 2$} & 0.021 & 0.027 & -0.019 & -0.012 & $0.120 * * *$ & 0.004 & 0.013 & $0.025^{*}$ & -0.012 & -0.004 & $0.150^{* * * *}$ & -0.024 \\
\hline & (0.018) & (0.017) & $(0.016)$ & (0.009) & (0.044) & $(0.023)$ & $(0.017)$ & $(0.015)$ & (0.013) & (0.008) & $(0.042)$ & $(0.021)$ \\
\hline \multirow[t]{2}{*}{ lp1 } & $0.773 * * *$ & $0.748 * * *$ & $0.840 * * *$ & $0.863 * * *$ & $0.695 * * *$ & $0.660 * * *$ & $0.828 * * *$ & $0.763 * * *$ & $0.870^{* * * *}$ & $0.876^{* * * *}$ & $0.731 * * *$ & $0.597 * * *$ \\
\hline & $(0.024)$ & $(0.022)$ & $(0.023)$ & $(0.010)$ & $(0.052)$ & $(0.044)$ & $(0.026)$ & $(0.023)$ & $(0.021)$ & $(0.010)$ & $(0.042)$ & $(0.045)$ \\
\hline \multirow[t]{2}{*}{ p1p1 } & $-0.028 * * *$ & $-0.083^{* * *}$ & 0.009 & $-0.035^{* * *}$ & $0.073^{* * *}$ & $-0.076^{* * *}$ & $-0.022 * * *$ & $-0.079 * * *$ & 0.003 & $-0.035 * * *$ & $0.094 * * *$ & $-0.089^{* * *}$ \\
\hline & $(0.007)$ & (0.009) & $(0.010)$ & $(0.006)$ & $(0.022)$ & $(0.026)$ & $(0.007)$ & $(0.009)$ & (0.008) & $(0.006)$ & $(0.021)$ & $(0.025)$ \\
\hline \multirow[t]{2}{*}{ p1q1 } & $-0.036 * * *$ & $-0.014 * *$ & 0.011 & -0.007 & -0.018 & -0.017 & $-0.024 * *$ & $-0.015 * * *$ & 0.005 & -0.003 & 0.009 & -0.018 \\
\hline & $(0.011)$ & $(0.006)$ & $(0.007)$ & $(0.005)$ & $(0.022)$ & $(0.015)$ & $(0.011)$ & $(0.005)$ & $(0.006)$ & $(0.004)$ & $(0.020)$ & $(0.012)$ \\
\hline \multirow[t]{2}{*}{ p1q2 } & 0.006 & $0.040^{* *}$ & -0.005 & -0.006 & 0.041 & $-0.089 * *$ & 0.013 & $0.042 * *$ & -0.009 & $-0.013^{*}$ & $0.072^{*}$ & $-0.064 *$ \\
\hline & $(0.017)$ & $(0.017)$ & $(0.016)$ & $(0.007)$ & $(0.042)$ & $(0.038)$ & $(0.017)$ & (0.017) & (0.013) & $(0.007)$ & $(0.041)$ & $(0.036)$ \\
\hline \multirow[t]{2}{*}{ lrisk } & 0.010 & 0.002 & $0.034 * * *$ & $0.040 * * *$ & 0.037 & $0.030^{* *}$ & 0.016 & -0.001 & $0.039 * * *$ & $0.033 * * *$ & 0.024 & 0.010 \\
\hline & (0.014) & (0.013) & $(0.011)$ & (0.008) & $(0.027)$ & $(0.012)$ & $(0.014)$ & $(0.013)$ & $(0.010)$ & $(0.007)$ & $(0.024)$ & (0.012) \\
\hline \multirow[t]{2}{*}{ Constant } & $-0.706 * * *$ & $-0.277 * * *$ & $-1.233 * * *$ & $-1.198 * * *$ & $-0.376 * * *$ & $-0.189 * *$ & -0.232 & $-0.359 * *$ & $1.265 * * *$ & $-0.697 * * *$ & $0.479 * *$ & $-0.795 * * *$ \\
\hline & (0.098) & (0.078) & $(0.070)$ & $(0.042)$ & (0.112) & (0.094) & $(0.241)$ & $(0.159)$ & $(0.285)$ & $(0.248$ & (0.188) & $(0.134)$ \\
\hline \multirow[t]{2}{*}{ Insigma2 } & 0.076 & $-0.578 * * *$ & $0.688 * * *$ & 0.027 & $-0.828 * * *$ & 0.001 & $-0.940 * * *$ & $-1.255 * * *$ & $-1.161 * * *$ & $-0.934 * * *$ & $-2.239 * * *$ & $-0.689 * * *$ \\
\hline & $(0.159)$ & $(0.195)$ & $(0.137)$ & $(0.101)$ & $(0.321)$ & $(0.155)$ & $(0.161)$ & $(0.189)$ & $(0.136)$ & $(0.103)$ & $(0.259)$ & (0.149) \\
\hline \multirow[t]{2}{*}{ gamma } & $2.743 * * *$ & $2.898 * * *$ & $3.987 * * *$ & $3.631 * * *$ & $2.087 * * *$ & $2.834 * * *$ & $1.551 * * *$ & $2.135 * * *$ & $2.074 * * *$ & $2.637 * * *$ & 0.335 & $2.110^{* * * *}$ \\
\hline & $(0.212)$ & $(0.254)$ & $(0.167)$ & $(0.126)$ & $(0.447)$ & $(0.203)$ & $(0.245)$ & $(0.257)$ & $(0.179)$ & $(0.134)$ & $(0.532)$ & $(0.202)$ \\
\hline $\mathrm{N}$ & 429 & 330 & 500 & 1101 & 127 & 496 & 429 & 330 & 500 & 1101 & 127 & 496 \\
\hline
\end{tabular}

*** and *** denote significances of $10 \%, 5 \%$ and $1 \%$, respectively. SFA denotes panel data stochastic frontier analysis while FE SFA include country dummies. Regions refer to "Africa" (1), "East Asia/Pacific" (2), "Europe/Central Asia" (3), "Latin America" (4), "Middle East/North Africa" (5) and "South Asia" (6). 
Table A4: Spearman Correlations of Efficiency Estimates by Region

\begin{tabular}{|c|c|c|c|c|c|c|c|c|c|c|c|c|c|}
\hline \multirow[t]{2}{*}{ Africa } & & \multicolumn{6}{|l|}{ Financial } & \multicolumn{6}{|l|}{$\begin{array}{c}\text { Multi- } \\
\text { Dimensional }\end{array}$} \\
\hline & & SFA & SFA-R & DFA & DEA & FE SFA & FE SFA-R & SFA & SFA-R & DFA & DEA & FE SFA & FE SFA-R \\
\hline \multirow[t]{6}{*}{ Financial } & SFA & 1.00 & & & & & & & & & & & \\
\hline & SFA-R & 0.94 & 1.00 & & & & & & & & & & \\
\hline & DFA & 0.97 & 0.98 & 1.00 & & & & & & & & & \\
\hline & DEA & 0.91 & 0.87 & 0.89 & 1.00 & & & & & & & & \\
\hline & FE SFA & 0.53 & 0.56 & 0.53 & 0.47 & 1.00 & & & & & & & \\
\hline & FE SFA-R & 0.56 & 0.63 & 0.59 & 0.49 & 0.97 & 1.00 & & & & & & \\
\hline \multirow[t]{6}{*}{ Multi-Dim } & SFA & 0.86 & 0.85 & 0.87 & 0.85 & 0.46 & 0.50 & 1.00 & & & & & \\
\hline & SFA-R & 0.92 & 0.97 & 0.95 & 0.86 & 0.53 & 0.60 & 0.93 & 1.00 & & & & \\
\hline & DFA & 0.85 & 0.89 & 0.90 & 0.81 & 0.48 & 0.54 & 0.96 & 0.96 & 1.00 & & & \\
\hline & DEA & 0.88 & 0.86 & 0.86 & 0.98 & 0.45 & 0.48 & 0.87 & 0.87 & 0.84 & 1.00 & & \\
\hline & FE SFA & 0.55 & 0.57 & 0.55 & 0.53 & 0.85 & 0.84 & 0.61 & 0.60 & 0.60 & 0.54 & 1.00 & \\
\hline & FE SFA-R & 0.60 & 0.66 & 0.63 & 0.56 & 0.90 & 0.94 & 0.62 & 0.68 & 0.63 & 0.55 & 0.94 & 1.00 \\
\hline
\end{tabular}

\begin{tabular}{|c|c|c|c|c|c|c|c|c|c|c|c|c|c|}
\hline \multirow[t]{2}{*}{$\begin{array}{l}\text { East Asia/ } \\
\text { Pacific }\end{array}$} & & \multicolumn{6}{|l|}{ Financial } & \multicolumn{6}{|l|}{$\begin{array}{c}\text { Multi- } \\
\text { Dimensional }\end{array}$} \\
\hline & & SFA & SFA-R & DFA & DEA & FE SFA & FE SFA-R & SFA & SFA-R & DFA & DEA & FE SFA & FE SFA-R \\
\hline \multirow[t]{6}{*}{ Financial } & SFA & 1.00 & & & & & & & & & & & \\
\hline & SFA-R & 0.97 & 1.00 & & & & & & & & & & \\
\hline & DFA & 0.98 & 0.92 & 1.00 & & & & & & & & & \\
\hline & DEA & 0.89 & 0.93 & 0.87 & 1.00 & & & & & & & & \\
\hline & FE SFA & 0.94 & 0.93 & 0.92 & 0.88 & 1.00 & & & & & & & \\
\hline & FE SFA-R & 0.89 & 0.94 & 0.85 & 0.88 & 0.96 & 1.00 & & & & & & \\
\hline \multirow[t]{6}{*}{ Multi-Dim } & SFA & 0.80 & 0.74 & 0.82 & 0.69 & 0.68 & 0.59 & 1.00 & & & & & \\
\hline & SFA-R & 0.73 & 0.73 & 0.74 & 0.65 & 0.61 & 0.57 & 0.96 & 1.00 & & & & \\
\hline & DFA & 0.84 & 0.76 & 0.89 & 0.72 & 0.73 & 0.63 & 0.96 & 0.89 & 1.00 & & & \\
\hline & DEA & 0.75 & 0.77 & 0.77 & 0.90 & 0.72 & 0.71 & 0.73 & 0.69 & 0.76 & 1.00 & & \\
\hline & FE SFA & 0.77 & 0.76 & 0.75 & 0.71 & 0.84 & 0.82 & 0.70 & 0.66 & 0.69 & 0.65 & 1.00 & \\
\hline & FE SFA-R & 0.62 & 0.65 & 0.61 & 0.60 & 0.70 & 0.72 & 0.63 & 0.66 & 0.60 & 0.57 & 0.94 & 1.00 \\
\hline
\end{tabular}




\begin{tabular}{|c|c|c|c|c|c|c|c|c|c|c|c|c|c|}
\hline \multirow[t]{2}{*}{$\begin{array}{l}\text { Europe/ } \\
\text { Central } \\
\text { Asia }\end{array}$} & & \multicolumn{6}{|l|}{ Financial } & \multicolumn{6}{|l|}{$\begin{array}{c}\text { Multi- } \\
\text { Dimensional }\end{array}$} \\
\hline & & SFA & SFA-R & DFA & DEA & FE SFA & FE SFA-R & SFA & SFA-R & DFA & DEA & FE SFA & FE SFA-R \\
\hline \multirow[t]{6}{*}{ Financial } & SFA & 1.00 & & & & & & & & & & & \\
\hline & SFA-R & 0.96 & 1.00 & & & & & & & & & & \\
\hline & DFA & 0.96 & 0.85 & 1.00 & & & & & & & & & \\
\hline & DEA & 0.87 & 0.89 & 0.78 & 1.00 & & & & & & & & \\
\hline & FE SFA & 0.48 & 0.38 & 0.54 & 0.40 & 1.00 & & & & & & & \\
\hline & FE SFA-R & 0.39 & 0.37 & 0.41 & 0.33 & 0.90 & 1.00 & & & & & & \\
\hline \multirow[t]{6}{*}{ Multi-Dim } & SFA & 0.94 & 0.91 & 0.91 & 0.80 & 0.44 & 0.34 & 1.00 & & & & & \\
\hline & SFA-R & 0.91 & 0.94 & 0.83 & 0.80 & 0.36 & 0.31 & 0.98 & 1.00 & & & & \\
\hline & DFA & 0.91 & 0.81 & 0.96 & 0.72 & 0.52 & 0.37 & 0.95 & 0.88 & 1.00 & & & \\
\hline & DEA & 0.88 & 0.88 & 0.79 & 1.00 & 0.40 & 0.33 & 0.81 & 0.82 & 0.74 & 1.00 & & \\
\hline & FE SFA & 0.40 & 0.30 & 0.48 & 0.30 & 0.90 & 0.83 & 0.45 & 0.37 & 0.52 & 0.32 & 1.00 & \\
\hline & FE SFA-R & 0.32 & 0.28 & 0.36 & 0.23 & 0.82 & 0.89 & 0.37 & 0.33 & 0.39 & 0.24 & 0.93 & 1.00 \\
\hline
\end{tabular}

\begin{tabular}{|c|c|c|c|c|c|c|c|c|c|c|c|c|c|}
\hline $\begin{array}{l}\text { Latin } \\
\text { America }\end{array}$ & & Financial & & & & & & $\begin{array}{c}\text { Multi- } \\
\text { Dimensional }\end{array}$ & & & & & \\
\hline & & SFA & SFA-R & DFA & DEA & FE SFA & FE SFA-R & SFA & SFA-R & DFA & DEA & FE SFA & FE SFA-R \\
\hline Financial & SFA & 1.00 & & & & & & & & & & & \\
\hline & SFA-R & 0.99 & 1.00 & & & & & & & & & & \\
\hline & DFA & 0.95 & 0.90 & 1.00 & & & & & & & & & \\
\hline & DEA & 0.91 & 0.93 & 0.79 & 1.00 & & & & & & & & \\
\hline & FE SFA & 0.69 & 0.68 & 0.64 & 0.59 & 1.00 & & & & & & & \\
\hline & FE SFA-R & 0.66 & 0.65 & 0.61 & 0.57 & 1.00 & 1.00 & & & & & & \\
\hline Multi-Dim & SFA & 0.74 & 0.71 & 0.76 & 0.65 & 0.36 & 0.33 & 1.00 & & & & & \\
\hline & SFA-R & 0.79 & 0.80 & 0.76 & 0.75 & 0.41 & 0.38 & 0.97 & 1.00 & & & & \\
\hline & DFA & 0.72 & 0.67 & 0.83 & 0.57 & 0.37 & 0.34 & 0.95 & 0.88 & 1.00 & & & \\
\hline & DEA & 0.84 & 0.84 & 0.77 & 0.93 & 0.50 & 0.47 & 0.77 & 0.82 & 0.69 & 1.00 & & \\
\hline & FE SFA & 0.56 & 0.54 & 0.55 & 0.46 & 0.85 & 0.84 & 0.48 & 0.49 & 0.48 & 0.47 & 1.00 & \\
\hline & FE SFA-R & 0.55 & 0.54 & 0.54 & 0.46 & 0.84 & 0.84 & 0.46 & 0.49 & 0.46 & 0.46 & 0.99 & 1.00 \\
\hline
\end{tabular}




\begin{tabular}{|c|c|c|c|c|c|c|c|c|c|c|c|c|c|}
\hline $\begin{array}{l}\text { Middle } \\
\text { East/ North } \\
\text { Africa }\end{array}$ & & Financial & & & & & & $\begin{array}{c}\text { Multi- } \\
\text { Dimensional }\end{array}$ & & & & & \\
\hline & & SFA & SFA-R & DFA & DEA & FE SFA & FE SFA-R & SFA & SFA-R & DFA & DEA & FE SFA & FE SFA-R \\
\hline \multirow[t]{6}{*}{ Financial } & SFA & 1.00 & & & & & & & & & & & \\
\hline & SFA-R & 0.94 & 1.00 & & & & & & & & & & \\
\hline & DFA & 0.97 & 0.98 & 1.00 & & & & & & & & & \\
\hline & DEA & 0.88 & 0.74 & 0.81 & 1.00 & & & & & & & & \\
\hline & FE SFA & 0.08 & 0.15 & 0.14 & 0.06 & 1.00 & & & & & & & \\
\hline & FE SFA-R & 0.10 & 0.26 & 0.20 & -0.02 & 0.92 & 1.00 & & & & & & \\
\hline \multirow[t]{6}{*}{ Multi-Dim } & SFA & 0.93 & 0.88 & 0.92 & 0.78 & 0.09 & 0.15 & 1.00 & & & & & \\
\hline & SFA-R & 0.81 & 0.85 & 0.85 & 0.65 & 0.10 & 0.20 & 0.89 & 1.00 & & & & \\
\hline & DFA & 0.96 & 0.96 & 0.98 & 0.79 & 0.11 & 0.18 & 0.97 & 0.90 & 1.00 & & & \\
\hline & DEA & 0.85 & 0.77 & 0.82 & 0.96 & 0.16 & 0.10 & 0.78 & 0.70 & 0.80 & 1.00 & & \\
\hline & FE SFA & 0.22 & 0.28 & 0.29 & 0.15 & 0.93 & 0.88 & 0.29 & 0.30 & 0.28 & 0.27 & 1.00 & \\
\hline & FE SFA-R & 0.21 & 0.31 & 0.28 & 0.10 & 0.61 & 0.68 & 0.33 & 0.46 & 0.31 & 0.18 & 0.67 & 1.00 \\
\hline
\end{tabular}

\begin{tabular}{|c|c|c|c|c|c|c|c|c|c|c|c|c|c|}
\hline \multirow[t]{2}{*}{ South Asia } & & \multicolumn{6}{|l|}{ Financial } & \multicolumn{6}{|l|}{$\begin{array}{c}\text { Multi- } \\
\text { Dimensional }\end{array}$} \\
\hline & & SFA & SFA-R & DFA & DEA & FE SFA & FE SFA-R & SFA & SFA-R & DFA & DEA & FE SFA & FE SFA-R \\
\hline \multirow[t]{6}{*}{ Financial } & SFA & 1.00 & & & & & & & & & & & \\
\hline & SFA-R & 0.96 & 1.00 & & & & & & & & & & \\
\hline & DFA & 0.98 & 0.94 & 1.00 & & & & & & & & & \\
\hline & DEA & 0.90 & 0.84 & 0.86 & 1.00 & & & & & & & & \\
\hline & FE SFA & 0.80 & 0.82 & 0.78 & 0.69 & 1.00 & & & & & & & \\
\hline & FE SFA-R & 0.75 & 0.83 & 0.70 & 0.68 & 0.94 & 1.00 & & & & & & \\
\hline \multirow[t]{6}{*}{ Multi-Dim } & SFA & 0.88 & 0.90 & 0.84 & 0.80 & 0.69 & 0.69 & 1.00 & & & & & \\
\hline & SFA-R & 0.89 & 0.96 & 0.86 & 0.80 & 0.75 & 0.79 & 0.96 & 1.00 & & & & \\
\hline & DFA & 0.95 & 0.94 & 0.95 & 0.83 & 0.73 & 0.69 & 0.96 & 0.95 & 1.00 & & & \\
\hline & DEA & 0.88 & 0.86 & 0.86 & 0.96 & 0.67 & 0.66 & 0.84 & 0.84 & 0.87 & 1.00 & & \\
\hline & FE SFA & 0.65 & 0.68 & 0.62 & 0.58 & 0.93 & 0.89 & 0.61 & 0.66 & 0.62 & 0.57 & 1.00 & \\
\hline & FE SFA-R & 0.69 & 0.76 & 0.65 & 0.63 & 0.90 & 0.95 & 0.68 & 0.76 & 0.67 & 0.64 & 0.95 & 1.00 \\
\hline
\end{tabular}

Notes: Correlations with DEA are calculated based on average efficiency scores of DEA across time. 